\title{
Health Implications of some Public Swimming Pools located in Port Harcourt, Nigeria
}

\author{
Agbagwa O. E*, Young-Harry, W. M \\ Department of Microbiology, Faculty of Science, University of Port Harcourt, East- West Road, Choba. P. M. B. 5323, Rivers State Nigeria
}

\begin{abstract}
A total of eight water samples were obtained from eight swimming pools. The water samples were tested for total heterotrophic plate count, total faecal coliform count, isolation and enumeration of Enterococci, Staphylococcus aureus and Pseudomonas aeruginosa. The $\mathrm{pH}$ residual chlorine and temperature of the water was also determined. Total Heterotrophic Bacterial Count was found to be highest in pool BOU to be $1.32 \times 109 \mathrm{cfu} / \mathrm{ml}$ and least THBC was EVE pool with counts of $8.0 \times 103 \mathrm{cfu} / \mathrm{ml}$. Staphylococcus aureus and Pseudomonas aeruginosa were the most predominant organisms in the pool with percentage occurrences of $31 \%$ and $25 \%$. Enterobacter, Citrobacter and Bacillus had percentage occurrences of $12 \%, 13 \%$ and $13 \%$. Klebsiella was the least in occurrence with a value of $6 \%$. The temperature range obtained from the pools were within the ranges of $23.7^{\circ} \mathrm{C}$ to $26.5^{\circ} \mathrm{C}$, the $\mathrm{pH}$ for the eight different pools were within the value of 7.0 to 8.5 and chlorine range was 0.001 to 4.10 .
\end{abstract}

Keywords Health, Swimming Pool, Recreational Water

\section{Introduction}

Recreational waters include swimming pools, whirlpools, and naturally occurring fresh and marine waters[1]. About one in five people urinate in public pools, only $23 \%$ of public pool users are concerned about the maintenance and care of the public pools. It has

been recorded that about $35 \%$ of people do not shower before jumping into the pool. There is an established link between water quality and swimming-associated illness risks. In the case of recreational waters where people have close contact with that water, the quality of water may affect people's health. Recreational waters may be contaminated by direct human contact and by waterborne pollutants from external sources (e.g., sewage, storm water and agricultural runoff). The primary concern is to protect human health by preventing water pollution from faecal material or from contamination by microorganisms that could cause gastro-intestinal illnesses, ear, eye or skin infections[2]. Public pools can infect individuals based on the fact that public pools do not use environmentally sound disinfectant agents in the water, rather brominating agents are used, when these brominating agent gets mixed with carbon- friendly substances such as urine, hair, skin, cosmetics and sunscreen it becomes toxic. And prolong exposure to pool water with these mixtures have been proven to cause gene mutations,

* Corresponding author:

ejiroagbagwa@yahoo.com (Agbagwa O. E)

Published online at http://journal.sapub.org/phr

Copyright (C) 2012 Scientific \& Academic Publishing. All Rights Reserved increase in aging process, respiratory aliments and possibly induce cancer.

Recreational waters are often contaminated by human sewage as a result of discharges or overflows[3]. Swimming in faecal contaminated recreational waters has consistently been associated with gastrointestinal (GI) illness[4]. The incidence of illness attributable to recreational water exposure appears to be increasing. The U.S. Centre for Disease Control and Prevention (CDC) reported 21 recreational water outbreaks in 2000 , more than any single previous year since systematic surveillance began[5]. The Natural Resources Defence Council[6] reported that there were more beach closings and advisories in 2000 than in any previous year; $85 \%$ of these closings and advisories were due to bacteria levels that exceeded standards. Because of the great diversity of pathogenic microorganisms transmitted by contaminated water and the difficulty and cost of directly measuring all microbial pathogens in environmental samples, organisms that may indicate the presence of sewage and faecal contamination (indicator organisms) are often used for monitoring and regulation of recreational and drinking waters. Indicator organisms are common inhabitants of the intestinal tract of warm-blooded animals. They are found in faecal material at high concentrations and are easier to measure in the environment than are pathogens. Although indicator organisms do not cause illness under normal conditions, they represent a measure of faecal contamination. Human sewage is a source of faecal contamination and also is known to contain pathogenic microorganisms [7; 8].

Currently recommended bacterial indicators are based on microbiological methods that involve culturing faecal 
indicator bacteria, such as Enterococcus spp. or Escherichia coli, and counting the colony-forming units. The overall goal of the current ambient water quality criteria (AWQC) for bacteria in the United States[3] is to provide public health protection from gastroenteritis associated with exposure to faecal contamination during water contact recreation. Because faecal matter can be a major source of pathogens in ambient water, and because it is not practical or feasible to monitor for the full spectrum of all pathogens that may occur in water, water quality criteria are specified throughout the world in terms faecal indicator organism densities[3; 2]. These faecal indicator organisms have been used for decades as surrogates for potential pathogens and subsequent health risks in both recreational and drinking waters[9]. The Agency used prospective cohort epidemiological studies of wastewater effluent-impacted recreational waters[3] to develop the 1986 American Water Quality Control for recreational water. The results of those epidemiological studies provide quantitative relationships between faecal indicator density in recreational waters (E. coli and enterococci for freshwaters and enterococci for marine waters) and GI illness levels for those individuals exposed to recreational waters[3; 14]. Internationally, many countries still rely on faecal and total coliforms as a basis for their recreational water quality criteria, standards, or guidelines[2; $11]$.

\section{Materials and Methods}

\subsection{Sample stations/collection of sample}

A total of eight pools were selected for the study, four of the pools are located within the University of Port Harcourt, Nigeria, while the other four are not located within the University. These swimming pools are busy with activities from the University students with little or no care giving to the maintenance of such pools.

Plastic 1 litre sample collection bottles was used to collect water from eight swimming pools in Port Harcourt metropolis coded as Sample stations PRH, ELC, BOU, LOT, CIV, UPH, EVE and CHA respectively. Sample contamination during collection was avoided and the bottles were properly labelled to avoid confusion. One litre (1L) of the water sample was collected from each sampling location, leaving ample space for effective shaking. Samples were transported in ice boxes to the laboratory and analysis carried out immediately.

\subsubsection{Sample Preparation}

Each plate was marked with sample number, dilution, name of media and date before examination. Triplicate plates for each volume of dilution examined were prepared. Sterile glass petri dishes were used for the spread plate method. All samples were thoroughly mixed by rapidly making back-and-forth movements.

\subsubsection{Microbiological Analysis}

Microbiological analysis was carried out on the water samples by carrying out bacteriological analysis which are as listed below.

\subsubsection{Heterotrophic Plate Count}

The Heterotrophic Plate Count (HPC) was carried out by estimating the number of viable heterotrophic bacteria in water and measuring changes during water treatment and distribution in swimming pools. Heterotrophic plate count was determined by spread plate method using nutrient agar as directed in Section 9215 (APHA 2005).

A ten-fold serial dilution was made up to 10-9. Sterile plates were labelled with the dilutions. Using a sterile pipette, $0.1 \mathrm{ml}$ of appropriate dilution was aseptically withdrawn and introduced into the dry agar surface of plate. A sterile glass rod was used to spread the suspension and plates were incubated in inverted position at $35^{\circ} \mathrm{C}$ for 24 hours. After the incubation period, number of colonies between $30-300$ was counted.

\subsubsection{Total and Faecal Coliform Count}

The coliform group consists of several genera of bacteria belonging to the family Enterobacteriaceae. When multiple tubes are used in the fermentation technique, results of the examination of replicate tubes are reported in terms of the Most Probable Number (MPN) of organisms present. This number, based on certain probability formulae is an estimate of the mean density of coliforms in the sample.

\section{Presumptive Phase}

Single and double strength solutions of MacConkey broth were prepared according to the manufacturer's instruction. $10 \mathrm{ml}$ of double strength solution was dispensed into 5 tubes while $9 \mathrm{ml}$ of single strength solution was dispensed into 10 tubes, durham tubes were inserted and autoclaved at $121^{\circ} \mathrm{C}$ for $15 \mathrm{mins} .10 \mathrm{ml}, 1 \mathrm{ml}$ and $0.1 \mathrm{ml}$ respectively of the test sample were inoculated into the appropriate tubes and incubated for 24 hours at $35^{\circ} \mathrm{C}$. A positive result for total coliform is confirmed by a change of colour and presence of trapped gas in the durham tubes.

\section{Confirmatory Test}

Brilliant green bile broth is used to confirm the presence of total coliforms. One loopful of the positive tubes from the presumptive test is inoculated into $10 \mathrm{ml}$ of sterile BGB broth and inoculated for 24 hours at $44^{\circ} \mathrm{C}$. A positive test for total coliforms is confirmed by a change in colour and presence of trapped gas in the durham tubes after the incubation period.

\section{Completed test}

Escherichia coli is a member of the faecal coliform group of bacteria and it indicates the presence of faecal coliforms. This organism in water indicated faecal contamination and possible presence of enteric pathogens. Test for E.coli was done using Eosin Methylene Blue (EMB) agar. $0.1 \mathrm{ml}$ aliquot of the water sample was inoculated into EMB plates and incubated at $44 \mathrm{oC}$ for 24 hours. After incubation, plates were observed for the presence of colonies with metallic green sheen. 


\subsubsection{Isolation and Enumeration of Enterococci}

The enterococcus group is a subgroup of the faecal streptococci that includes S. faecalis, S. faecium, S. gallinarium and $\mathrm{S}$. avium. The enterococci are differentiated from other streptococci by their ability to grow in $6.5 \%$ sodium chloride, at $\mathrm{pH} 9.6$, and at $10^{\circ} \mathrm{C}$ and $45^{\circ} \mathrm{C}[1]$. The enterococci portion of the faecal streptococcus group is a valuable bacterial indicator for determining the extent of faecal contamination of recreational surface waters. Isolation of enterococci was done using Slanetz and Bartley's medium. The medium was prepared according to manufacturer's specification and boiled. It was allowed to cool, poured into sterile Petri dishes and let to set. Aliquot of $0.1 \mathrm{ml}$ of the water sample was inoculated into the plates and spread using a sterile hockey stick. The plates were incubated for $24 \mathrm{hrs}$ at $44{ }^{\circ} \mathrm{C}$. After incubation, presence of enterococci was identified by pink colonies.

\subsubsection{Isolation and Enumeration of Staphylococcus aureus}

S. aureus was isolated using Mannitol Salt Agar according to APHA 2005. The medium was prepared according to manufacturer's specification and autoclaved at $121^{\circ} \mathrm{C}$ for 15 minutes. After autoclaving, it was poured into plates and allowed to set. Aliquot of $0.1 \mathrm{ml}$ of the water sample was inoculated into the plates and spread using a sterile hockey stick. The plates were incubated for $24 \mathrm{hrs}$ at $37^{\circ} \mathrm{C}$. After incubation, presence of $\mathrm{S}$. aureus was identified by yellow-cream colonies.

\subsubsection{Isolation and Enumeration of Pseudomonas Aeruginosa}

P. aeruginosa was isolated using King A medium. The medium was weighed according to manufactures procedure and autoclaved at $121^{\circ} \mathrm{C}$ for 15 minutes. After autoclaving, it was poured into plates and allowed to set. Aliquot of $0.1 \mathrm{ml}$ of the water sample was inoculated into the plates and spread using a sterile hockey stick. The plates were incubated up to 7 days at $37^{\circ} \mathrm{C}$ and checked for bacteriological growth after 24-48 and 72 hours and then after 6 days. Colonies of Pseudomonas aeruginosa appeared surrounded by a blue to green zone.

\subsection{Culture Purification and Characterization}

A pure culture is essential for accurate identification. Pure cultures were obtained by carefully picking a well-isolated colony that gave a typical response on nutrient agar plate. Plates were incubated at $35^{\circ} \mathrm{C}$ for 24 hours. Pure cultures are stored in the fridge prior to characterization. The purified cultures were Gram - stained and the following biochemical tests were carried out for identification. They include indole test, Methly red and Voges- Proskaeur test, motility test, catalase, sugar fermentation test and hydrogen sulphide production.

\subsection{Physico-Chemical Analyses}

\subsubsection{Determination of Temperature, $\mathrm{pH}$ and Residual Chlorine}

The temperature of the sample was recorded with a mercury-in-glass thermometer at the site of sample collection by dipping the thermometer into the water samples collected.

The $\mathrm{pH}$ of the water samples were measured using a $\mathrm{pH}$ meter. The glass electrode was first inserted in a standard phosphate buffer solution of $\mathrm{pH}$ 7.0. The electrode was the immersed into the samples and the readings were taken.

The chloride in neutral or weakly saline solution containing chromate is titrated against silver nitrate. Silver chloride precipitates. The end point is reached by the formation of silver chromate.

\section{Results and Discussion}

\subsection{Enumeration of Bacteria in Recreational Water Samples}

The results of the frequency of total heterotrophic bacteria count of the eight water samples collected from swimming pools in Port Harcourt metropolis are shown in Table 1. Swimming Pool BOU was found to be the highest contaminated with total microbial count of 1.32 x $109 \mathrm{cfu} / \mathrm{ml}$ while that of Swimming Pool EVE is the least contaminated with microbial count of $8.0 \times 103 \mathrm{cfu} / \mathrm{ml}$. Figure 1 shows the distribution of S.aureus and P.aeruginosa from the different recreational water sources. S.aureus and P.aeruginosa were most predominant in swimming pool BOU while swimming pools UPH had the lowest occurrence of S. aureus and P. aeruginosa. Swimming pools EVE and $\mathrm{CHA}$ had no occurrence of S.aureus and P. aeruginosa. Figure 2 shows the percentage distribution of bacterial isolates from the different recreational water sources. S.aureus was the most predominant (31\%) while Klebsiella $\mathrm{sp}$ was the least dominant $(6 \%)$. The total coliform counts from the various sample locations is detailed in Table 2, results reveal that swimming pool BOU have the highest coliform counts of $20 \mathrm{MPN} / 100 \mathrm{ml}$ while swimming pool EVE and CHA had the least coliform counts of $<2 \mathrm{MPN} / 100 \mathrm{ml}$.

The occurrence of bacteria in the different recreational water sample locations is represented in Table 3 . Table 4 indicates the physicochemical characteristics of the different water samples. The temperature range of the water samples was between $23.7^{\circ} \mathrm{C}-26.5^{\circ} \mathrm{C}$. The $\mathrm{pH}$ of the water samples were not within the WHO (2003) acceptable range of $7.0-$ 8.5 except Swimming pools PRE, ELC, EVE and CHA. The residual chlorine ranged between $0.01-4.10 \mathrm{mg} / 1$. 


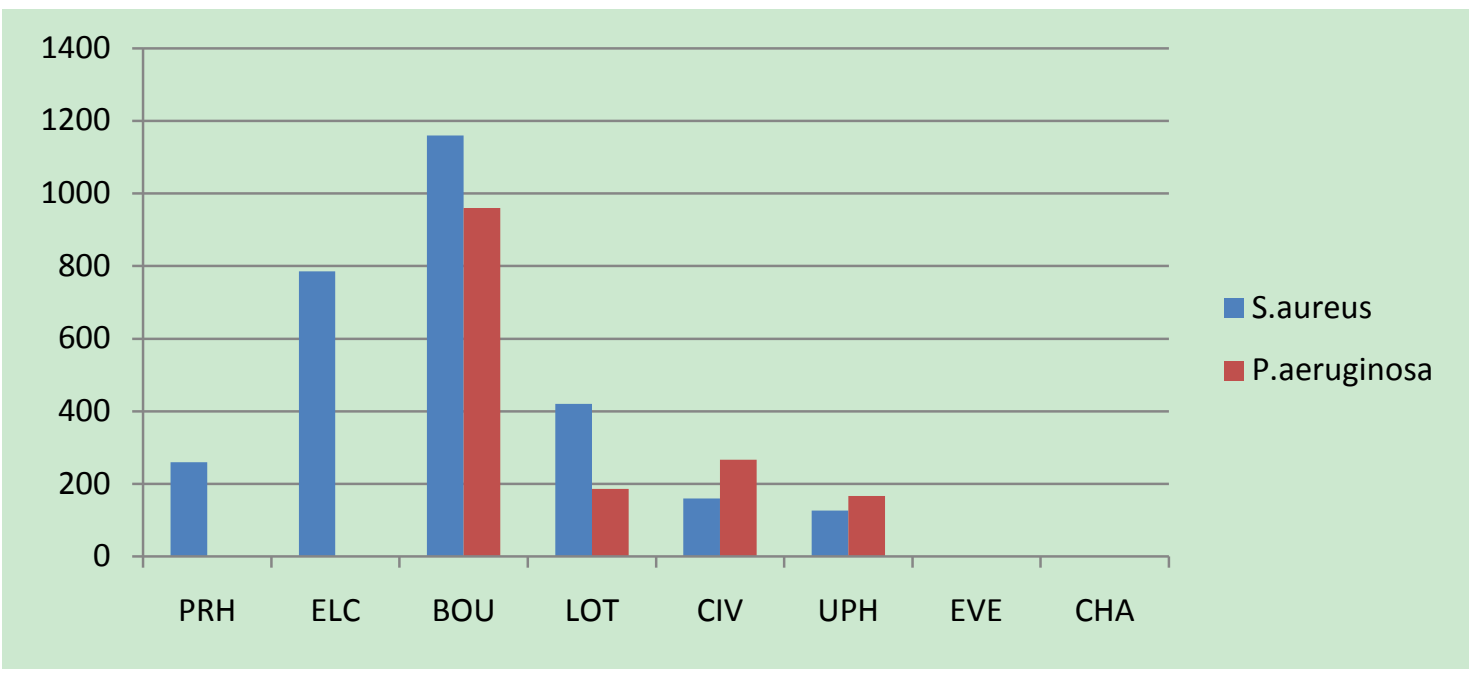

Figure 1. Histogram showing the distribution of S. aureus and P. aeruginosa from the different recreational water sources

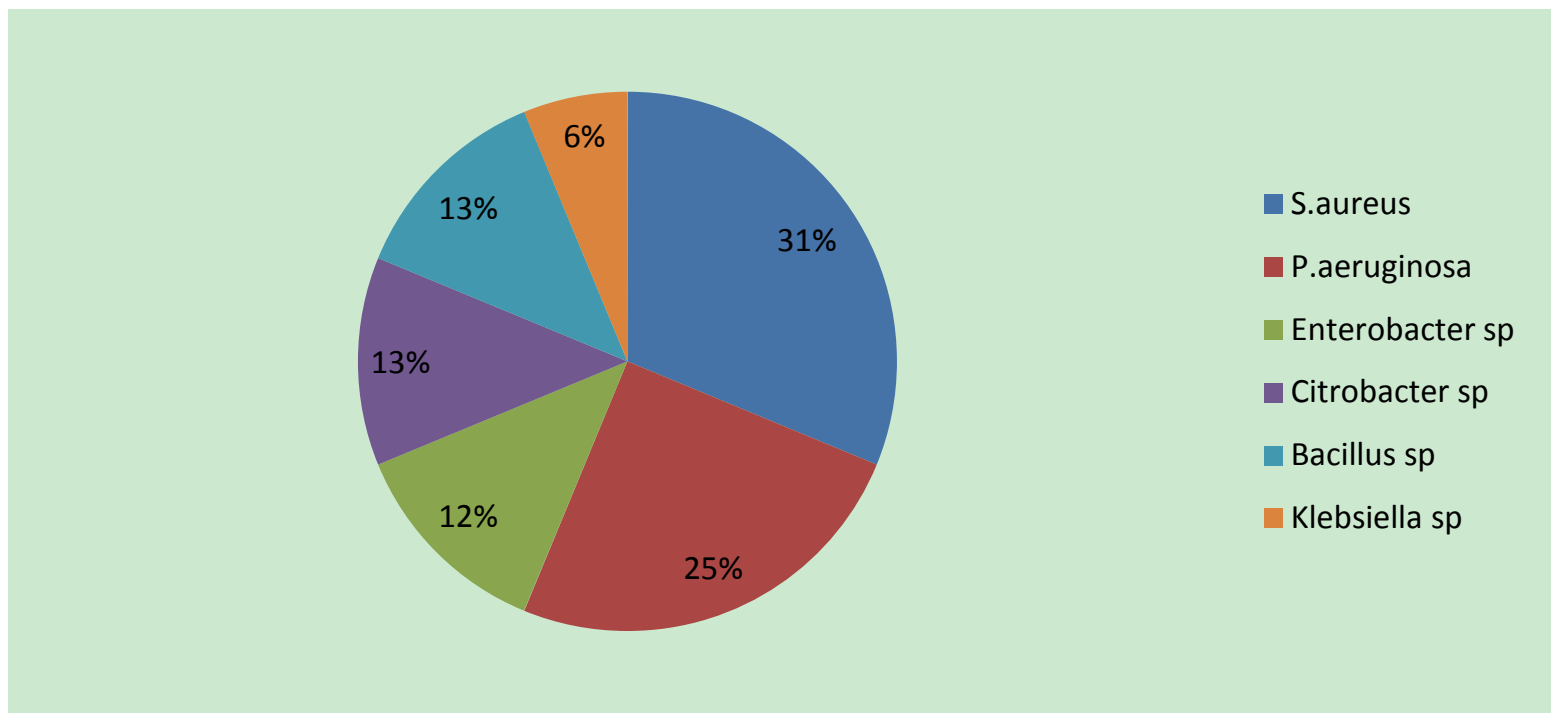

Figure 2. Percentage distribution of bacterial isolates from sample areas

Table 1. Frequency of Total Viable Counts from Different Sample Locations

\begin{tabular}{|cccc|}
\hline Sample code & Average no of colonies & Df & cfu/ml \\
\hline PRH & 35 & 103 & $3.5 \times 105$ \\
ELC & 113 & 104 & $1.13 \times 107$ \\
BOU & 132 & 106 & $1.32 \times 109$ \\
LOT & 98 & 105 & $9.8 \times 107$ \\
CIV & 101 & 105 & $1.01 \times 108$ \\
UPH & 43 & 103 & $4.3 \times 105$ \\
EVE & 8 & 102 & $8.0 \times 103$ \\
CHA & 17 & 102 & $1.7 \times 104$ \\
\hline
\end{tabular}

Table 2. Total Coliform Counts from Different Sample Locations

\begin{tabular}{|ccccc|}
\hline Sample code & $10 \mathrm{ml}$ & $1 \mathrm{ml}$ & $0.1 \mathrm{ml}$ & MPN/ $100 \mathrm{ml}$ \\
\hline PRH & 1 & 0 & 0 & 2 \\
ELC & 1 & 1 & 0 & 4 \\
BOU & 3 & 3 & 1 & 20 \\
LOT & 1 & 0 & 0 & 2 \\
CIV & 3 & 1 & 2 & 4 \\
UPH & 1 & 1 & 0 & $<2$ \\
EVE & 0 & 0 & 0 & $<2$ \\
CHA & 0 & 0 & 0 & 4 \\
\hline
\end{tabular}

Table 3. Occurrence of Bacteria in the Different Sample Stations 


\begin{tabular}{|c|c|c|c|c|c|c|c|c|}
\hline \multirow[t]{2}{*}{ Organisms } & \multicolumn{3}{|c|}{ Sample Stations } & \multirow[b]{2}{*}{ LOT } & \multirow[b]{2}{*}{$\mathrm{CIV}$} & \multirow[b]{2}{*}{ UPH } & \multirow[b]{2}{*}{ EVE } & \multirow[b]{2}{*}{$\mathrm{CHA}$} \\
\hline & PRH & ELC & $\mathrm{BOU}$ & & & & & \\
\hline S.aureus & + & + & + & + & + & + & - & - \\
\hline P.aeruginosa & - & - & + & + & + & + & - & - \\
\hline Bacillus sp & + & + & + & + & + & + & + & + \\
\hline Citrobacter sp & + & - & + & + & + & + & - & - \\
\hline Klebsiella sp & - & + & + & + & + & + & - & - \\
\hline Enterobacter sp & + & + & + & + & + & + & - & - \\
\hline
\end{tabular}

LEGEND -ve $=$ Absent + ve $=$ Present

Table 4. Physicochemical Characterization of the Different Water Samples

\begin{tabular}{|cccc|}
\hline Sample codes & $\mathrm{pH}$ & Temperature (oC) & Residual Chlorine (mg/l) \\
\hline PRH & 7.20 & 24.3 & 3.70 \\
ELC & 7.90 & 26.5 & 3.85 \\
BOU & 5.60 & 25.5 & 1.05 \\
LOT & 5.73 & 25.2 & 3.45 \\
CIV & 6.50 & 23.7 & 0.01 \\
UPH & 5.35 & 24.8 & 0.01 \\
EVE & 7.85 & 26.1 & 3.90 \\
CHA & 7.64 & 25.4 & 4.10 \\
\hline
\end{tabular}

The main objective of this study was to evaluate the quality of water from different recreational waters (swimming pools) sources in Port Harcourt metropolis. Heterotrophic plate counts and Coliform counts have been used extensively as a basis for regulating the microbial quality of recreational waters. In this study, both regulatory parameters were excessively above the WHO guideline values. Study results clearly indicated that most of the recreational water sources are highly contaminated. The detection of pathogenic enteric bacteria in different locations of recreational waters in Port Harcourt also reveals the alarming situation for swimming associated gastroenteritis in the area. Water quality indicates that pollution of the water is increasing alarmingly and that it has created serious threat to human health and environment.

The microbiological analyses of the pools showed high occurrence of bacteria count in most of the swimming pools. The heterotrophic plate count (HPC) indicates that sample station BOU had the highest microbial load after $24 \mathrm{~h}$ of incubation having a value of $1.32 \times 109 \mathrm{cfu} / \mathrm{ml}$. This high bacterial count might be due to constant usage of the pool by the students of the University of Port Harcourt. The HPCs for all the water samples were generally high, exceeding the limit of $1.0 \times 102 \mathrm{cfu} / \mathrm{ml}$ for water. The most probable number (MPN) for the presumptive total coliform count of the water samples ranges from $<2$ to $20 \mathrm{MPN} / 100 \mathrm{ml}$. It indicates that water from sample station $\mathrm{BOU}$ had the highest total coliform counts of $20 \mathrm{MPN} / 100 \mathrm{ml}$ followed by sample station CIV having $17 \mathrm{MPN} / 100 \mathrm{ml}$.

The results of this study indicate that micro-organisms are present in the different swimming pools. The bacterial species isolated from the recreational water samples are shown in Table 3. Of all the organisms isolated, only Bacillus sp appeared in all the sample locations. The percentage distribution of bacterial population isolated includes S. aureus (31\%), P.aeruginosa(25\%), Bacillus $\mathrm{sp}(13 \%), \quad$ Kleibsella $\mathrm{sp}(5 \%), \quad$ Citrobacter $\quad \mathrm{sp}(13 \%)$, Enterobacter sp (12\%). The appearance of $\mathrm{S}$ aureus having the highest in occurrence is in conformity with other studies carried out[10]. The presence of these organisms in high number in the pools may be attributed to the time of collection of the samples when pools are most heavily used. Lack of disinfection of pools can also be responsible for this[11].

The risk of illness or infection associated with swimming pools, spas and similar recreational water environments has been linked to faecal contamination of the water due to faeces released by bathers or contaminated source water[1; 10]. Many of the outbreaks related to swimming pools have occurred because disinfection was poorly or not at all applied. The majority of reported swimming pool-related outbreaks have been caused by viruses; recently, however, reported outbreaks have been more frequently associated with bacteria and protozoa. As well as pathogenic enteric organisms, a number of infectious non-enteric organisms may be transferred in recreational-water environments, via human shedding (e.g., from saliva or mucus discharges). Infected users can directly contaminate pool or spa waters and the surfaces of objects or materials at a facility with primary pathogens (notably viruses or fungi) in sufficient numbers to consequently lead to skin and other infections in patrons who come in contact with the contaminated water or surfaces[12]. Opportunistic pathogens (notably bacteria) can also be shed from users and transmitted via contaminated water in pools or spas. In addition, certain free living aquatic bacteria and amoebas can grow in pool or spa waters, in pool or spa components or facilities (including heating, ventilation and air conditioning $[\mathrm{HVAC}]$ systems) or on other wet surfaces within the facility to a point at which they may cause a variety of respiratory, dermal or central nervous system infections or diseases[2].

The $\mathrm{pH}$ has a direct impact on the recreational users of 
water only at very low or very high values[1]. Studies carried out in Jordan on the sanitary conditions of pools revealed that there was a poor compliance with to standards which resulted to high residual chlorine and $\mathrm{pH}[13]$. Under these circumstances, $\mathrm{pH}$ may have effects on the skin and eyes. Primary irritation of the skin appears to be linked to high $\mathrm{pH}$, although the mechanism is unclear. It is unlikely that irritation or dermatitis would be caused directly by high or low $\mathrm{pH}$, although these conditions may be exacerbated, particularly in sensitive subjects. Water of high $\mathrm{pH}$ could have an adverse effect on hair condition by causing the hair fibres to swell and by cleaving the cystine bridges between adjacent polypeptide chains of hair protein. However, the impact will also be dictated by the buffering capacity of the water. In very soft and poorly buffered waters with an alkalinity of less than about $40 \mathrm{mg}$ of calcium carbonate per litre, $\mathrm{pH}$ will be more susceptible to wide fluctuations. In well buffered waters, $\mathrm{pH}$ is much less likely to reach extreme values, but the significance of high or low $\mathrm{pH}$ for skin reactions and eye irritation will be greater[14].

The temperature of the study areas ranged between $23.7^{\circ} \mathrm{C}$ and $26.5^{\circ} \mathrm{C}$. The contact time temperature is inversely related to the water temperature. Thus, as the temperature increases, chlorine dosage required to inactivate the microbiological organism's decreases. The temperature relations may be invalid for bacteria which thrive at elevated temperature[1]. The study on swimming pools can help monitor out breaks within the pool had been well managed and effectively monitored $[15 ; 16]$.

A variety of disinfectants are used for pool water treatment. Those used most frequently in large, heavily used pools include chlorine, ozone and chlorine in combination and chlorine dioxide; less frequently used disinfectants include bromine and iodine. There are three main routes of exposure to chemicals in swimming pools or spa waters inhalation of volatile or aerosolized solutes, dermal contact and direct ingestion of the water. For chlorine-based disinfectants, adequate routine disinfection should be achieved with a free chlorine residual level of at least 1 $\mathrm{mg} /$ litre throughout the pool[1]. The residual chlorine for the sample areas ranged between $0.01-4.10 \mathrm{mg} / \mathrm{L}$. majority of the recreational waters sampled were within the acceptable range of at least $1 \mathrm{mg} / \mathrm{L}$ except $\mathrm{UPH}$ and CIV sample areas[17].

The best way to safe guard against nasty toxicity of public pools is to advice individuals not to urinate into pools, individuals should be advised to shower before jumping into the pool.

\section{Conclusions}

The result obtained in this study indicates that most of the swimming pools in Port Harcourt are not properly and regularly treated. The least polluted is swimming pool EVE while the most polluted is swimming pool BOU. Recreational water quality should be controlled in order to minimise acute problems of swimming-associated illnesses.

\section{REFERENCES}

[1] APHA (2005). Standard Methods for the Examination of Water and Wastewater, 21st edition. American Public Health Association, Washington, DC.

[2] WHO (2003). Guidelines for Safe Recreational Water

[3] Environments Volume 1 Coastal and Fresh Waters, World Health Organization, Geneva. USEPA (2001) Ambient water quality criteria for bacteria, United States Environmental Protection Agency, Washington DC.

[4] Wade, T.J., Pai, N., Eisenberg, J.N.S., Colford, J.M. (2003). Do U.S. Environmental Protection Agency water quality guidelines for recreational waters prevent gastrointestinal illness? A systematic review and meta-analysis. Environmental Health Perspectives 111(8): 1102-1109.

[5] Lee, S.H., Levy, D.A., Craun, G.F., Beach, M.J., Calderon, R.L. (2002). Surveillance for waterborne-disease outbreaks-United States, 1999-2000. Mortality and Morbidity Weekly Report CDC Surveillance Summaries 51(8): 1-47.

[6] Zmirou, D., Pena, L., Ledrans, M., Letertre, A. (2003). Risks for recreational purposes: summary estimates based on published epidemiological studies. Archives of Environmental Health 58(11): 703-711.

[7] Griffin, D.W, Donaldson, K.A, Paul, J.H, Rose, J.B. (2003).

[8] Pathogenic human viruses in coastal waters. Clin Microbiol Rev 16(1):129-143.

[9] Jones, M., Boccia, D., Kealy, M., Salkin, B., Ferrero, A., Nichols, G., Stuart, J.M. (2006). Cryptosporidium outbreak linked to interactive water feature, UK: importance of guidelines. EuroSurveillance 11(4): 126-128.

[10] NRC (2004). National Research Council Indicators for Waterborne Pathogens. National Academies Press: Washington, DC.

[11] Papadopoulou C, Economou V, Sakkas H, Gessouli H, Karanis P, Leveidiotou S, Giannakopoulos X, Dontorou C, Filioussis G. (2008). Microbiolgical quality of indoor and outdoor pools in Greece: Investigation of the antibiotic resistance of bacterial isolates. Int J Hyq. 211: 385-97.

[12] Maida C. M, Di Benedetto M. A, Firenze A, Calamusa G, Di Piazza F, Romano N. (2008). Surveillance of the sanitary conditions of a public swimming pool in the city of Palermo (Italy), 4(5): 581-93.

[13] Bilajac L, Lusic D. V, Jelinic D. J, Ruvarina T (2012). Microbiological and chemical indicators of water quality in indoor hotel swimming pools before and after training of swimming pool operators. Journal of water and Health, 10: 108-115.

[14] Rabi A, Khander Y, Alkafaja A, Abu Aqoulah A (2008). Sanitary conditions of public swimming pools in Amman Jordan. Int. J. Environ Res Public Health, 5(3): 152-157.

[15] Nikaeen M, Hatamzaded M, Valid Dastjerdi M, Hassanzadeh 
A (2009). Predictive Indicators of the safety of swimming pool waters. Water Sci Technol, 60(12) 3101-7.

[16] Mina K. D and Gerba C. P (2009). Risk assessement of Pseudomonas aeruginosa in water (2009). Rev Environ Contam Toxicol, 20: 71- 115.

[17] Sule I. O, Oyeyiola G. P (2010). Biological Assessement of some swimming pools within Ilorin metropolis, Kwara of Nigeria. Bioresearch Bulletin, 1: 29- 33.

[18] Cappello A. M. (2011). Assessing bacteriological contamination of public swimming facilities within Colorando Metropolitan Community. Adap phyd Actv, 28(1) 1-5. 